\title{
El Servicio Exterior durante la Organización Nacional de la República Argentina a través de la trayectoria diplomática de Manuel Rafael García (1860-1880)
}

Walter Rubén Derbiz*

Fecha de Recepción: 8 de julio de 2021

Fecha de Aceptación: 22 de septiembre de 2021

DOI: https://doi.org/10.46553/RGES.57.2021.p.40-61

\begin{abstract}
Resumen
El artículo recupera buena parte de la trayectoria diplomática de Manuel Rafael García. Pone de manifiesto las expectativas personales y políticas del actor -identificado con el sector de liberales nacionalistas porteños de mediados de la década del cincuenta-, y sus relaciones con las dirigencias de la Confederación, en su acceso al Servicio Exterior. Aborda el amplio marco de acción puesto de manifiesto por el diplomático en su posicionamiento ante el recambio presidencial de 1868 y aspira a ofrecer una mayor comprensión del proceso histórico y algunas de las funciones, en sus etapas iniciales, de esa particular esfera estatal.
\end{abstract}

Palaras clave: Estado; Relaciones Exteriores; Servicio Exterior; Diplomáticos

\begin{abstract}
The article recovers a good part of the diplomatic career of Manuel Rafael García. It reveals the personal and political expectations of the actor -identified with the liberal nationalist sector of Buenos Aires in the mid-1850s, and his relations with the Confederation leaderships, in his access to the Foreign Service. It addresses the broad framework of action revealed by the diplomat in office prior to the 1868 presidential replacement and aims to offer a greater understanding of the historical process and some of the early-stage functions of that state level.
\end{abstract}

Keywords: State; Foreign Relations; Foreign Service; Diplomats

\section{Introducción}

La profunda renovación historiográfica argentina de los últimos años vinculada a los estudios sobre el Estado, evidencian el aún incompleto abordaje desde diferentes aproximaciones temáticas y metodológicas. Sin embargo, las reflexiones dan cuenta de las maneras en que la construcción Estatal fue desafiada en procesos que distaron de ser homogéneos o lineales. ${ }^{1}$

\footnotetext{
* Universidad Nacional de Mar del Plata, Centro de Estudios Históricos (Cehis)

${ }^{1}$ Véase los estudios de Ernesto Bohoslavsky y Germán Soprano, Un Estado con rostro humano. Funcionarios $e$ instituciones estatales en Argentina (desde 1880 hasta la actualidad) (Buenos Aires, Prometeo-UNGS, 2010); Beatriz Bragoni, San Martín. Una biografía política del libertador (Buenos Aires: Edhasa, 2019); Beatriz Bragoni y Eduardo Miguez, Un nuevo orden político. Provincias y Estado Nacional, 1852-1880 (Buenos Aires: Biblos, 2010); Pablo Bunchbinder, Caudillos de pluma y hombres de acción. Estado y política en Corrientes en
} 
El vacío es aún mayor en la historiografía acerca de la experiencia e institucionalización del trabajo al interior de las legaciones diplomáticas dado que, en líneas generales, quienes tradicionalmente han abordado esa función estatal, lo han hecho desde disciplinas afines a las relaciones internacionales o el derecho. El trabajo de Beatriz Solveira aborda el desenvolvimiento institucional del Ministerio de Relaciones Exteriores y la expansión de las legaciones y los consulados por el mundo desde 1853 y $1930 .^{2}$ En los últimos años han emergido en el campo de la historiografía, resultados de investigaciones que, desde distintos marcos epistemológicos, iluminan la trayectoria de algunos diplomáticos que se desempeñaron en la última década del siglo XIX e inicios del XX. ${ }^{3}$

Se aborda aquí, desde una perspectiva biográfica y relacional, el Servicio Diplomático Argentino que Manuel Rafael García contribuyó a delinear, desde su interior, durante las presidencias de Mitre, Sarmiento y Avellaneda.

La extensa trayectoria de este actor en el servicio exterior (a partir de 1863 hasta su muerte en 1887) reviste un significativo interés puesto que no ha sido atendida aún por la historia diplomática, la historia de las relaciones internacionales o la historiografía sobre las múltiples aristas de las funciones estatales. Además, se enlazan a través de él cuatro generaciones de una familia de funcionarios estatales: Pedro Andrés García (1758-1833), Manuel José García (1784-1844), Manuel Rafael García (1826-1887), y sus hijos Manuel José García Mansilla (1859-1910) y Daniel García Mansilla (1867-1957). El enlace matrimonial con Eduarda Mansilla - hija de Agustina Rosas (1816-1898) y Lucio Norberto Mansilla (1792-1871) - favoreció, con su savoire faire, la tarea del diplomático en Washington entre 1861-1862 durante el estudio del funcionamiento de la Justicia Federal, y en 1868-1872,

tiempos de la Organización Nacional (Buenos Aires: Prometeo, 2004); José Carlos Chiaramonte Mercaderes del litoral. Economía y sociedad en la provincia de Corrientes, primera mitad del siglo XIX (México y Buenos Aires: Fondo de Cultura Económica, 1991); José Carlos Chiaramonte Ciudades, Provincias Estados: Orígenes de la Nación Argentina 1800-1846 (Buenos Aires: Compañía Editora Espasa Calpe, 1997); Ariel De la Fuente, Los hijos de Facundo. Caudillos y montoneras en la provincia de La Rioja durante el proceso de formación del estado nacional argentino (1853-1870) (Buenos Aires: Prometeo, 2007); Hernán Gonzáles Bollo, La fábrica de las cifras oficiales del Estado argentino (1869-1947) (Bernal: Editorial de la Universidad Nacional de Quilmes, 2014); Ana Laura Lanteri, Se hace camino al andar Dirigencia e instituciones nacionales en la "Confederación" (Argentina, 1852-1862) (Rosario: Prohistoria, 2015); Mariano Plotkin y Eduardo Zimmermann, Los saberes del Estado (Buenos Aires: Edhasa, 2012); Roberto Schmit, Ruina y resurrección en tiempos de guerra: sociedad, economía y poder en el Oriente entrerriano posrevolucionario, 1810-1852 (Buenos Aires: Prometeo, 2004).

${ }^{2}$ Solveira, Beatriz. La evolución del Servicio Exterior Argentino entre 1852 y 1930. Córdoba: Centro de Estudios Históricos, 1997.

3 Véase Juan Scarfi, "Diplomacia, vida cultural y circulación de saberes", disponible en http://historiapolitica.com/dossiers/diplomacia-circulacion-saberes/2015; Paula Bruno, "Vida diplomática, funciones estatales e identidades en tensión en el giro del siglo XIX al XX. Agenda de investigación, propuestas y usos de las fuentes", Revista Electrónica de Fuentes y Archivos (REFA) Centro de Estudios Históricos "Prof. Carlos S. A. Segreti” " n¹1, 2020. 
consolidada su propia trayectoria como literata, atrajo la atención de la prensa periódica norteamericana en torno de las actividades de la legación argentina. ${ }^{4}$ Por todo ello, el abordaje de la figura de Manuel Rafael García a partir de la utilización de distintos tipos de fuentes oficiales (instrucciones diplomáticas, memorias del Ministerio de Relaciones Exteriores, registro oficial, leyes de presupuesto) y especialmente la correspondencia privada intercambiada con un puñado de actores con destacadas trayectorias políticas como Félix Frias, Vicente Fidel López, Rufino de Elizalde, Domingo Faustino Sarmiento, Juan María Gutiérrez o su primo y administrador, Manuel Alejandro Aguirre, permiten poner de manifiesto las dinámicas presentes en la configuración del servicio diplomático constituido a partir de la Organización Nacional y responder los interrogantes: ¿Cuáles fueron las tareas de los primeros diplomáticos de la República unificada? ¿Cuáles fueron las estrategias puestas de manifiesto en la selección o el mantenimiento de los Enviados durante los recambios presidenciales y de ministros? ¿Qué percepción tuvieron los actores de su propia tarea?

El abordaje del papel de las personas y sus relaciones en la generación de institucionalidad a partir de la mutua interacción, permiten capturar la articulación de las expectativas personales del funcionario de residir junto a su familia en el extranjero invirtiendo recursos materiales y simbólicos en la construcción de una carrera en el servicio exterior, con las necesidades del propio Estado y de su burocracia en formación.

\section{Algunos rasgos biográficos}

Manuel Rafael García nació en Buenos Aires el 10 de noviembre de 1826, hijo de Manuel José García y Manuela Aguirre. Su padre, diplomático durante la presidencia de Rivadavia, firmó la Convención Preliminar de Paz que pondría fin a la guerra con el Brasil acordando la independencia de Uruguay en un escenario de crisis política desatada por la angustiante situación económica de nuestro país y la denuncia del centralismo del gobierno entre los cuales el gobernador de Córdoba, Juan Bautista Bustos, se erigía como principal vocero de la facción federal, todo lo cual desencadenaría en la renuncia del Presidente. La extensa y, desde su perspectiva, poco valorada o incomprendida trayectoria del padre fue objeto de las reflexiones del hijo a través de publicaciones en forma de artículos que

\footnotetext{
${ }^{4}$ Desde hace algunos años, la crítica literaria ha revisitado la obra y la figura de Eduarda Mansilla, posibilitando la reedición de algunas obras de ficción y periodísticas de la autora.
} 
respaldaba con documentos del significativo archivo heredado, que luego facilitó a Juan María Gutiérrez y Vicente Fidel López para sus propios trabajos. ${ }^{5}$

Perteneció a la generación de jóvenes formados en la Universidad de Buenos Aires durante el gobierno de Juan Manuel de Rosas de la cual egresó en 1846. Culminada la formación académica, su primer viaje a Europa le posibilitó adquirir experiencias y conocer a los parientes radicados en España desde la Revolución de Mayo a quienes administraba sus bienes en el Río de la Plata, tarea que continuó desarrollando hasta su alejamiento definitivo de Buenos Aires ${ }^{6}$.

En un clima de agitaciones políticas por las amenazas de guerra entre los gobiernos de la Confederación y Buenos Aires, contrajeron matrimonio Manuel Rafael García y Eduarda Mansilla. Su hijo Daniel refirió años más tarde: “Cuando mis padres se casaron, el día 31 de enero de 1855, dijo un diario de Montevideo que tratábase del enlace de Romeo y Julieta, por cuanto él era claramente de filiación unitaria, siendo mi madre, en cambio sobrina carnal del Restaurador"7. La realidad debió presentar algunos matices dado que esa identificación podría corresponder con la trayectoria de Manuel José García - abuelo del autor de la cita - en la década de los años veinte, insuficiente para explicar la participación posterior de dicho actor como funcionario del gobierno de Juan Manuel de Rosas. Asimismo, como ha señalado Beatriz Bragoni, en el periodo transcurrido entre Caseros y Pavón habría existido cierto grado de diversificación en torno de las estrategias matrimoniales de individuos cuyas familias mantuvieron diferencias políticas, generando alianzas a través de matrimonios de familias aparentemente opuestas, pero que están socialmente imbricados en sus características tanto económicas como sociales. ${ }^{8}$

\section{Actividad política dentro de los liberales nacionalistas porteños}

\footnotetext{
${ }^{5}$ La restitución de la figura pública del padre, que falleció cuando Manuel tenía 22 años, constituyó un tema recurrente en su correspondencia privada con Vicente Fidel López. Entre las publicaciones destacan el Ensayo biográfico de la vida pública del ciudadano D. Manuel José García, publicado en 1854 en El Plata Científico y Literario bajo la dirección de Navarro Viola; y hacia 1883 Documentos inéditos del Dr. Manuel José García diputado de las Provincias Unidas en la Corte del Janeiro. Época de Pueyrredón.

${ }^{6}$ En el fondo Manuel José García del Archivo General de la Nación se localizan las cartas emitidas desde Badajoz por su tía materna Casimira, casada con José Laguna, defensor del bastión realista, fallecido en 1828.

${ }^{7}$ Daniel García Mansilla, Visto, oído y recordado apuntes de un diplomático argentino (Buenos Aires: Kraft, 1950), 22.

${ }^{8}$ Beatríz Bragoni, Los hijos de la revolución: familia, negocios y poder en Mendoza en el siglo XIX (Buenos Aires: Taurus, 1999).
} 
El epistolario reconstruido se encuentra en su mayoría inédito y disperso en diversos archivos. ${ }^{9}$ Desde el punto de vista metodológico, un abordaje posible consiste en explorar la vida de Manuel Rafael García a partir de la información contenida en las cartas, emergiendo así los recorridos por países, relaciones familiares, inversiones patrimoniales, u observar la continuidad y recreación de los vínculos amicales. Otro tipo de aproximación más centrada en la subjetividad del actor posibilita apreciar las expectativas, dudas e incertidumbres sobre su futuro profesional y, a lo largo de su residencia en el extranjero, la necesidad de construir narraciones que den un sentido de continuidad con las personas frente a los cambios de lugares, objetos y personas.

Las cartas que dirigió desde Buenos Aires a Vicente Fidel López en Montevideo y a Juan María Gutiérrez en Paraná durante el año 1858, expresan su desencanto por el triunfo de Adolfo Alsina como gobernador de Buenos Aires, uno de los principales exponentes del sector de liberales afines a la separación del Estado respecto de la Confederación, lo cual implicaba el aplazamiento de la unificación nacional. Precisamente, esas cartas, que no debían someterse a un uso público u oficial, permiten vislumbrar el trabajo de construcción política y de lealtades personales que ligaron a ese grupo de hombres entre Buenos Aires y Paraná. Al estímulo ofrecido por Vicente Fidel López, García le respondía:

"Me dice Ud. que hagamos algo. El momento es decisivo, pero ¿Quiere que le hable con el corazón? Mil veces he combinado medios de arrancarme de esta apatía mortal, de crearme un entusiasmo capaz de arrastrar a otros que, con mejores medios, aunque con no mayor patriotismo sacuda a esta sociedad enferma de miedo y pequeñas y malas facciones, pero me acobardo al pensar en los elementos con que es indispensable contar. Imagínese que me destaco ¿en qué? En leer y traducir Horacio ad populum Romanum ¿qué le parece a los 32 años? ¿Pensaban así su padre y el mío? No ¡Viene Dios! ¡Y que cuenta damos de sus infatigables esfuerzos, de sus grandes esperanzas, de nuestras bellas ilusiones! Lo que es de imperiosa necesidad es un periódico que dirija la opinión, que haga pensar y enseñe cuales y cuántos son los intereses reales del país." 10

\footnotetext{
${ }^{9}$ Se han localizado al presente de 167 cartas enviadas por Manuel Rafael García a Juan Bautista Alberdi, Felix Frias, Juan María Gutiérrez, Vicente Fidel López y Rufino de Elizalde entre 1858 y 1883, y 131 que fueron recibidas por él entre 1850 y 1884. Las dirigidas a Gutiérrez se encuentran en la Biblioteca del Congreso de la Nación Argentina; las enviadas a Rufino de Elizalde pueden consultarse online en el repositorio digital del Instituto de Historia Argentina y América Dr. Emilio Ravignani; las dirigidas a Juan Bautista Alberdi se ubican en el Centro de investigaciones filológicas Jorge M. Furt; y las restantes, se localizan en distintos fondos del Archivo General de la Nación, principalmente el Fondo Los López y el fondo Manuel José García.

${ }^{10}$ Archivo General de la Nación (en adelante AGN), Fondo los López. Carta de García Manuel Rafael a Vicente Fidel López. Buenos Aires, Buenos Aires, 28 de setiembre de 1858.
} 
Más allá del rol que pudiera desempeñar en el proyecto propuesto por Vicente López, de las dificultades en el financiamiento de la empresa, del peso real o imaginado de la figura del padre, el diagnóstico acerca de la necesidad de crear un periódico "que dirija la opinión" se encuentra en consonancia con las prácticas que sustentaban el sistema republicano. ${ }^{11}$

Además comienzan a aparecer expresiones tales como "estoy tan desesperado de mi propio destino en este país que daría todo por volver a tomar las fuerzas que me faltan en cualquier rincón de la tierra...necesito salir de esta atmosfera para ocuparme de algo más digno que llenar papel sellado y protestar respecto a jueces ignorantes y necios". ${ }^{12}$ Un hombre que a los treinta y dos años confesaba al amigo no encontrar algo en qué destacarse más que en el estudio, casado con una joven mujer que daba inicio a su carrera literaria, abrumado por su rol como Juez Civil... Todo sumado a la muerte de su madre, ocurrida el año anterior, cuyo vínculo familiar era el último que lo ligaba a Buenos Aires, y el mantenimiento de las relaciones con los parientes en España... Todo ello, ¿en qué medida incidían en la idea de retomar las fuerzas en cualquier rincón de la tierra?

El resultado de la batalla de Cepeda y el Pacto de San José de Flores al año siguiente, ofrecía la perspectiva de la ansiada, por estos actores, unión nacional. El Presidente de la Confederación Santiago Derqui y el Gobernador de Buenos Aires Bartolomé Mitre, para afianzar el acercamiento de los liberales que preferían mantener la separación, acordaron "nombrar a los antiguos representantes porteños en cargos diplomáticos. Uno de los que más llamaron la atención fue precisamente el de Mariano Balcarce como Encargado de Negocios argentino en París". ${ }^{13}$ Balcarce era una figura conocida en los círculos de funcionarios y diplomáticos cercanos a los gobiernos europeos, ya que, como representante del Estado de Buenos Aires, buscó lograr el reconocimiento internacional para Buenos Aires o, como señala Figallo, "estorbar las negociaciones que pudiera llevar adelante Alberdi, e inclusive impedir el reconocimiento español hasta tanto se solucionara el problema nacional". ${ }^{14}$ Médico de profesión, descendiente de un General victorioso de las guerras por la Independencia y casado con Mercedes San Martin, reunía en torno a sí mismo la atención de quienes comparaban a su suegro con Aníbal o Napoleón en el cruce de los Alpes. ${ }^{15}$

\footnotetext{
${ }^{11}$ Alberto Lettieri, "La República de la opinión. Poder político y sociedad civil de Buenos Aires entre 18521861”. Revista De Indias, n²10 [https://doi.org/10.3989/revindias.1997.i210.787]

12 AGN. Carta de García Manuel Rafael a Vicente Fidel López, Buenos Aires, setiembre de 1858.

13 James Scobie, La lucha por la consolidación de la Nacionalidad Argentina. 1852-1862 (Buenos Aires: Librería Hachete S.A, 1964), 293.

${ }^{14}$ Beatriz Figallo, "Argentina" en Ruptura y reconciliación. España y el reconocimiento de las independencias latinoamericanas, Coord. Carlos Malamud (Madrid: Fundación Mapfre y Santillana Ediciones Generales, 2012), 219-268.

${ }^{15}$ Bragoni, San Martín, 230.
} 
Cerca del gobierno de Estados Unidos fue designado Domingo Faustino Sarmiento y Manuel Rafael García como Secretario, a quien se sumaba la comisión de estudiar de la Justicia Federal en ese país, circunstancia que no aceptaba por la oposición de sus respectivas facciones:

"Al Sr Mitre le dije francamente que interesaba su amistad con el fin de independizarme en lo posible del Enviado. Le he escrito al Sr. Riestra. No tengo contestación y este silencio me tiene en un estado de incertidumbre muy violento. Escribo al Sr Pico pidiendo que si se deciden a nombrarme recuerde que según lo acordado mi objeto principal es la Comisión propuesta y aceptada". ${ }^{16}$

La crisis que se desarrollaba en la provincia de San Juan, teatro de operaciones del enfrentamiento de federales y liberales radicalizados - vinculados estos últimos a Sarmiento-, profundizaba el rechazo de García hacia el Enviado pese a lo cual no planteaba desistir de la Comisión, sólo de la Secretaría de la legación: “forzado, amigo mío a abandonar mi país, mis amigos, mi carrera, no puedo dejar escapar a la única tabla que me ofrece una carrera honorable, en la que puedo ser útil a mi país y satisfacer mis estudios favoritos". ${ }^{17}$

\section{El Ministerio de Relaciones Exteriores y la política exterior durante la organización nacional}

A partir de la caída de Juan Manuel de Rosas en Caseros, Justo José de Urquiza dio impulso a un proceso de organización del poder central en base al programa que Juan Bautista Alberdi esbozó en Bases y puntos de partida para la organización política de la República Argentina, siendo este el modelo que inspiró la Constitución Nacional de 1853 (en adelante $\mathrm{CN})$.

Por su parte el organigrama del Ministerio de Relaciones Exteriores, con el cual funcionó en sus aspectos esenciales hasta los años ochenta, se configuró casi al día siguiente de la batalla de Caseros. Así, el 1 de marzo de 1852, durante el Gobierno Provisorio de la "Confederación Argentina"18 se dispuso que la dependencia estaría compuesta por siete empleados: un Oficial Mayor, un Oficial Primero, un Oficial de Ministerio Encargado del

\footnotetext{
${ }^{16}$ Biblioteca del Congreso de la Nación (en adelante BCN). Fondo Juan María Gutiérrez. Carta de Manuel Rafael García a Juan María Gutiérrez. Buenos Aires, 12 de enero de 1860.

${ }^{17}$ BCN. Carta de Manuel Rafael García a Juan María Gutiérrez, Buenos Aires, enero de 1860.

${ }^{18}$ Seguimos a Lanteri cuando señala como inexacto el término "Confederación" para describir la organización política posterior a la vigencia de la Constitución Nacional, dada la conformación, a partir de allí en un Estado Federal. Al igual que la investigadora utilizamos entrecomillado aquí y en adelante sin comillas.
} 
Archivo, dos Oficiales de Ministerio, dos Oficiales auxiliares; un portero y un ordenanza. ${ }^{19}$ Por entonces el titular de la dependencia fue el abogado Luis José de la Peña, exiliado durante el rosismo de cincuenta y seis años, cargo que, durante la escisión de Buenos Aires de la Confederación también desempeñó Juan María Gutiérrez, actor con quien García mantuvo un nutrido intercambio epistolar durante todo el periodo.

Al igual que en el modelo norteamericano, la Constitución no explicitaba cómo se concebía la función administrativa ni cómo debía ejercerse. Cualquier hombre mayor de edad podía acceder a un puesto sin otro requisito que la idoneidad (art. $16 \mathrm{CN}$ ). El presidente contaba con atribuciones para nombrar y remover a los magistrados plenipotenciarios y encargados de Negocios con acuerdo del Senado y por sí solo nombrar y remover a los ministros del despacho, los oficiales de sus secretarías, los agentes consulares y demás empleados de la administración (art. $86 \mathrm{CN}$ ). Tampoco podía crear empleos o fijar remuneraciones, siendo esta una función del Congreso (art. $67 \mathrm{CN}$ ).

La estructura y el número de empleados de la Confederación se mantuvo bajo la gestión del ministro Rufino de Elizalde durante la presidencia de Bartolomé Mitre. El 1 de enero de 1872, habiendo transcurrido cuatro años del gobierno de Sarmiento, entró en vigencia un nuevo esquema administrativo en virtud del cual se crearon tres secciones para dividir las tareas de la dependencia: 1) Legaciones y Consulados Argentinos; 2) Autoridades Nacionales, Provinciales y Particulares; y 3) Legaciones y Consulados Extranjeros. Cada una de ellas se constituyó con un oficial y un escribiente: Pedro Beláustegui - Antero Carrasco en la primera; José María Sagasta Isla - Ricardo Pio Figueroa en la segunda y Emilio Lamarca Juan Mason en la tercera ${ }^{20}$ Entre quienes contaban con mayor antigüedad destacan Beláustegui desde el 11/04/1852, Sagasta Isla desde 15/12/1862 y Figueroa desde el 19/09/1867. Los restantes empleados ingresaron al ministerio junto con las reformas. Si bien los documentos no revelan los motivos detrás de los cambios organizacionales o del personal de la dependencia, pareciera equilibrarse la jerarquía de los oficiales con diez y veinte años en el organismo respecto del recién incorporado Emilio Lamarca, que, por su formación en Gran Bretaña y Alemania, resultaba idóneo para desempeñarse al frente de la Sección "Legaciones y Consulados extranjeros".

Finalmente, la escasa diferenciación de funciones entre los empleados, sumado al tiempo que debía transcurrir hasta que los ingresantes pudieran alcanzar algún grado de

\footnotetext{
${ }^{19}$ Registro Oficial de la República Argentina (en adelante R.O.), Tomo Tercero. Buenos Aires: Imprenta de la República, 1882.

${ }^{20}$ R.O Tomo quinto (Buenos Aires: Imprenta de la República, 1884), 232.
} 
autonomía, permite especular que la designación de un responsable al frente de cada Sección facilitaría en parte la tarea de los ministros en cuanto a la distribución, supervisión y corrección del trabajo de los dependientes, criterio que parece profundizarse en el último tramo de la administración de Nicolás Avellaneda con la incorporación de la Sección "Secretaría". Los empleados Pedro Beláustegui y José Sagasta Isla perduraron ante la incorporación de quienes completarían la dotación. Además, se implementaron criterios organizacionales sobre la duración de la jornada de trabajo, metodologías para el registro de las actuaciones y del funcionamiento en general de la dependencia:

"El despacho ordinario de cada una de las secciones, correrá a cargo del Jefe, quien deberá consultar con el Subsecretario u oficial $1^{\circ}$ en ausencia de aquel, cuando el asunto sea de importancia u ofrezca dudas. Las comunicaciones que estén en idioma extranjero se entregarán al traductor, antes de darle entrada y luego de traducidas seguirán el trámite dispuesto. Ocurriendo algún trabajo que no pueda ser atendido por la Sección a que pertenezca, con la urgencia y dedicación necesarias, el SubSecretario asignará los empleados que deban agregarse a ella mientras dure aquel" 21

En cuanto a las legaciones diplomáticas, como ha señalado Liliana Brezzo, la escasez de recursos para incrementar su número priorizó la presencia permanente del Estado en la comunidad internacional cerca de los gobiernos de España, Francia, Gran Bretaña e Italia y los Estados Unidos. ${ }^{22}$ ¿De qué manera se articularon en la práctica las funciones políticas y administrativas para seleccionar a las personas adecuadas y asegurar la eficacia del servicio público? En ese sentido, parecería que el sistema de los contrapesos, es decir, la intervención del Congreso en la designación o remoción de los diplomáticos, adquiere un relieve particular, promoviendo la neutralidad frente los favoritismos o los vínculos familiares o personales, aspecto señalado para el sistema norteamericano donde "la intervención senatorial se manifiesta como un reaseguro contra las decisiones intempestivas de un presidente que, a partir de su elección, podría inclinarse a ubicar a sus propios hombres en detrimento de aquellos que, teniendo capacidad, hubieran sido nombrados en un periodo anterior". ${ }^{23}$ Desde otra perspectiva podría pensarse que la permanencia de los funcionarios tendería al acaparamiento de poder por parte de esos actores frente a los titulares del Ejecutivo.

\footnotetext{
${ }^{21}$ R.O Tomo Octavo (Buenos Aires: Taller tipográfico de la Penitenciaría, 1896), 162.

${ }^{22}$ Liliana Brezzo, "Intimidades de una diplomacia: el Ministerio de Relaciones Exteriores de la Confederación (1854-1860)", Todo es Historia, n³22, 1994.

${ }^{23}$ Dreyfus, Francoise La invención de la burocracia. Servir al Estado en Francia, Gran Bretaña y los Estados Unidos. Siglos XVIII-XX (Buenos Aires: Bblos 2012), 60.
} 
Lo que se observa al interior del Ministerio de Relaciones Exteriores en este período es una dinámica mixta. Por un lado, los empleados del Ministerio propiamente dicho dan cuenta de la transitoriedad de su paso por la administración, mientras que por otro lado, los funcionarios y el personal de las dos legaciones diplomáticas con sede en París y Washington gozaron de mayor estabilidad y con ello también la institucionalización de la política exterior. La estabilidad política inaugurada a partir de Pavón y el triunfo del librecambio en materia económica, acompañaron las oportunidades de crecimiento del comercio exterior, el auge de la economía del litoral, la atracción de mano de obra y el aumento de población.

De esa forma, de acuerdo a partir del gobierno de Mitre, la política de ligar comercio exterior con los mercados promovió la reglamentación del servicio consular y la apertura de nuevas oficinas que llegarían. Siguiendo a Solveira a 99 en 1862, 145 en 1870 y 236 en $1880 . .^{24}$

Sin embargo, frente a una mirada retrospectiva que podría dar la impresión de una política del Estado de permanencia y estabilidad de sus funcionarios en el exterior, nuestro argumento sostiene el peso y el margen de acción del propio García en el sostenimiento de su trayectoria, como parte de un proyecto personal más amplio ligado a residir con su familia en el extranjero.

\section{El primer contacto con la sociedad norteamericana}

Algunas de las impresiones causadas por el contacto con la sociedad norteamericana en 1861 quedaron registradas en los Recuerdos de Viaje de Eduarda Mansilla. Comenzaba la guerra de secesión, en las calles los gritos de los boletineros que anunciaban la marcha de los acontecimientos resonaban sin cesar, la revista de doscientos mil hombres, los trenes repletos de soldados y el desolador aspecto de la ciudad de Washington convertida en campamento conformaban un panorama desolador. A diferencia de Sarmiento, que encontraba en esa sociedad un ejemplo de progreso, el diplomático encontraba un mal en el materialismo que sumía a las instituciones, opinión meditada a través del tiempo: "Pronto verá Ud. unas observaciones sobre los Estados Unidos en 1870 que acabo de redactar para curarnos de idólatras y de señalar los abismos a que puede conducirnos una indiscreta imitación, como también los medios de hacer practicar las instituciones escritas, que nada son sin el organismo

\footnotetext{
${ }^{24}$ Solverira, "El Servicio Exterior", 181-182.
} 
que las vivifica". ${ }^{25}$ El matrimonio compartía su mirada crítica hacia esa sociedad: "La historia de ese país, como sus monumentos, es toda de ayer, de ahí la pobreza relativa que impresiona desagradablemente al viajero que llega de Europa, si bien comprende toda la riqueza y poderío que esa parte del Nuevo Mundo encierra. Halla mucho que le sorprende, pero poco que le seduzca". ${ }^{26}$

Las habilidades sociales de Eduarda Mansilla en la interacción con esposas e hijos, pero también con políticos, funcionarios, jueces y diplomáticos acreditados cerca de ese gobierno, contribuía con la tarea del esposo en el desarrollo de su tarea de reunir información sobre la historia y el funcionamiento de la justicia federal a la vez acrecentaba sus propios capitales culturales y relacionales.

¿Por qué se consideraba importante estudiar el funcionamiento de la justicia federal norteamericana? En la imaginación de los políticos liberales argentinos que gravitaban en la construcción de la República a finales de los años cincuenta, los desarrollos institucionales de los Estados Unidos no pasaban desapercibidos y debían ser conocidos tanto para imitarlos como para rechazarlos, en función de la experiencia local. ${ }^{27}$

Esa primera experiencia en el exterior dejó en el futuro diplomático la impresión de la falta de interés de los políticos hacia su trabajo, aún de quienes, formando parte del gobierno, lo habían designado específicamente: "Nadie me ha acusado recibo ni siquiera de los once meses de correspondencia... No sé si me iré a vivir a Italia, pues no pienso volver a Buenos Aires por mil razones que sería largo detallar". ${ }^{28}$ Finalizada la comisión, publicó en Florencia los resultados de sus investigaciones en un libro de poco más de cien páginas titulado Estudios sobre la aplicación de la Justicia Federal Norteamericana, dedicándolo a Bartolomé Mitre y Dalmacio Vélez Sarsfield: “Las publicaciones en idioma extranjero son muy difíciles y muy costosas como es natural suponerlo. No he querido ni indicar al Gobierno si desea tomar algunos ejemplares. Ud. me conoce heredero legítimo de mi padre sobre esta particularidad"29

Con ello aspiraba a mostrar su capacidad intelectual de lo cual derivara algún nuevo encargo oficial con el cual complementar los ingresos para continuar desarrollando el plan de

\footnotetext{
${ }^{25}$ BCN. Fondo J.M.G. Carta de Manuel Rafael García a Juan Manuel Gutiérrez, Washington, 23 de marzo de 1871.

${ }^{26}$ Eduarda Mansilla, Recuerdos de viaje (Buenos Aires: Ediciones el Viso, 1884), 34.

27 Eduardo Zimmerman, "Centralización, Justicia Federal, y construcción del Estado en la Organización Nacional", Revista de Instituciones, Ideas y Mercados, no 46, 2007, 271.

${ }^{28}$ BCN. Fondo J.M. Gutiérrez. Carta de Manuel Rafael García a Juan Manuel Gutiérrez, Washington, 15 de marzo de 1862.

${ }^{29}$ BCN. Fondo J.M. Gutiérrez. Carta de Manuel Rafael García a Juan Manuel Gutiérrez, París, julio de 1863.
} 
vivir con su familia en el exterior. Sin embargo, a la falta de recepción oficial de su trabajo, se sumarían problemas, una vez publicado, con el arribo de los ejemplares a Buenos Aires:

"Poco afortunado he sido con la publicación de la primera parte de mis estudios sobre la justicia federal. No sacaré provecho, ni honra. Esto último me desalienta extraordinariamente a continuar la publicación de la segunda parte que creo no carece de interés, pues en ella he tratado de deslindar las relaciones del Gobierno General y el local, materia que ha dado ya ocasión a nuestro apreciadísimo Rawson a refutar las herejías federales de Sarmiento sobre el estado de sitio."30

Los destinatarios de sus apreciaciones continuaban siendo Juan María Gutiérrez y Vicente Fidel López, entre quienes podía expresar libremente sus sentimientos y al igual que Alberdi, desalentaba la copia de instituciones que podrían no llegar a obtener los resultados esperados en la Argentina, con lo cual mantenía sus prevenciones respecto de Sarmiento:

"muchos libros sobre derecho constitucional americano son obra del partido que ha puesto a la patria de Washington en el estado en que la vemos. Sarmiento, que se considera profundo conocedor de la Constitución americana, sigue las opiniones más desacreditadas en muchos puntos como lo ha demostrado recientemente". 31

\section{El acceso al Servicio Exterior}

El nombramiento oficial como secretario de la legación argentina cerca de los gobiernos de España, Francia, Gran Bretaña e Italia coronó las expectativas de García luego del transcurso de meses a la espera en Europa. Ello fue posible en virtud al cumplimiento de las promesas efectuadas por Mitre previas a su salida de Buenos Aires y mediante el despliegue de dinámicas de intermediación personal desarrolladas en Buenos Aires por Lucio Victorio Mansilla y Manuel Alejandro Aguirre Ituarte, el suegro y el administrador respectivamente:

"Después de eso había estado a verme Don Santiago Albarracín quien me dijo que iba a interponer su influencia para que te diesen algún empleo en Italia, que el general Mansilla se lo había pedido, diciéndole que tú ya no aceptarás más si te fuese renovada tu comisión para Norteamérica, por haberte retirado de allí.

\footnotetext{
${ }^{30}$ BCN. Fondo J.M. Gutiérrez. Carta de Manuel Rafael García a Félix Frías, París, 6 de octubre de 1863.

${ }^{31}$ BCN. Fondo J.M. Gutiérrez. Carta de Manuel Rafael García a Juan Manuel Gutiérrez, París, 17 de febrero de 1864.
} 
Supongo que a la fecha nada se ha obtenido por el lado de Albarracín, porque él me ofreció avisarme oportunamente para que yo te escribiese si obtenía lo que se proponía. Al Dr. Vélez, hacen días que no lo veo, pero confío más por este lado que por ningún otro, a no ser el mismo Mitre que no te olvida". ${ }^{32}$

El 18 de mayo de 1863, a través de la designación de los miembros de las dos legaciones diplomáticas del Estado argentino cerca de los gobiernos de España, Francia, Gran Bretaña e Italia y de los Estados Unidos, el presidente Bartolomé Mitre continuó, en materia de política exterior, los lineamientos iniciados entre Buenos Aires y la Confederación en 1860 ratificando a los mismos titulares designados en aquella oportunidad. Si bien Balcarce y García habían formado parte de facciones enfrentadas no se suscitaron los problemas derivados de la designación junto a Sarmiento.

Las instrucciones diplomáticas demandaban la modificación del Tratado celebrado entre España y la Confederación el 9 de Julio de 1857 ya que, al encontrarse la provincia de Buenos Aires separada de la Confederación, no lo había aceptado e inclusive había protestando contra el mismo, resultando que "hoy el tratado es obligatorio para trece provincias y nulo y sin valor en la principal que es Buenos Aires" y en lo atinente a la ciudadanía "la república no puede declinar ni declinará del principio de ciudadanía natural consignado en la Constitución".33

El 21 de septiembre de 1863 se logró la modificación que en Argentina se presentó como un Tratado nuevo, aprobado legislativamente y promulgado por el presidente. ${ }^{34}$ Juan Bautista Alberdi, protagonista del tratado anterior, en un folleto de 46 páginas publicado en París, titulado Diplomacia de Buenos Aires y los intereses Americanos y Europeos en el Plata, exponía en forma crítica las razones por las que entendía que se trataba de un error que acarrearía funestas consecuencias para el país al sumar ciudadanos con el destino de engrosar el poder militar, pero no de formar una ciudadanía. Ello fue replicado por el Secretario de la legación, el propio García, quien lo impugnó con otro de 24 páginas publicado en Madrid.

¿Se trataba de una modificación de la identidad política en función a su nuevo rol? A juzgar por la continuidad de los vínculos epistolares con Juan María Gutiérrez y Vicente Fidel López, más bien parecería formar parte de una oportunidad para demostrar una vez más sus cualidades y consolidar el posicionamiento "los asuntos de la Legación me proporcionan por

\footnotetext{
${ }^{32}$ AGN. Fondo José Manuel García, Legajo 1134. Carta de Alejandro Aguirre Ituarte, a Manuel Rafael García. Buenos Aires, 24 de octubre de 1863.

${ }^{33}$ Siegrist de Gentile, Norma Instrucciones diplomáticas argentinas:1820-1874 (Córdoba: Centro de Estudios Históricos, 1997), 97

${ }^{34}$ Figallo, "Argentina", 231.
} 
el momento la oportunidad de ganar más tarde una charretera", ${ }^{35}$ le comentaba al amigo desde París.

Los viajes a España eran aprovechados para cumplir encargos de Gutiérrez que consistían en su mayoría en reunir documentos para sus investigaciones sobre el pasado colonial:

"Cuente Ud. con lo que pueda hacer en favor de su proyecto reservado. Muchas facilidades me presentarían mis relaciones y parentelas en España, especialmente en Sevilla, para colectar datos preciosos, pero es materialmente imposible hacer nada serio corriendo la posta de una Legación nómada y ... pobrísimamente retribuida para el Secretario que poco suyo tiene para vivir con la decencia que exige su puesto. ¿Quiere Ud. creer que tengo que disputar los términos clarísimos de la ley y que no me reconocen sobresueldos por servir 4 Legaciones? ${ }^{36}$

Su sueldo como Secretario hacia 1865 se calculaba en \$F 5652 anuales y el del Ministro Plenipotenciario en \$F 8472, pero, de acuerdo a las manifestaciones de su apoderado en Buenos Aires se abonaban con retraso:

“el 27 de ppdo me entregaron por tus sueldos hasta fin de este año descontando la comisión del pagaré 54 onzas de oro y espero que no harán esperar mucho ya por lo asignado por instalación y tal vez algo más pues me había hecho dar esperanzas el Ministro Elizalde de algunas migajas para gastos de viaje", 37

La moderación de las remuneraciones implicaba que solo los hombres que tuvieran medios de existencia asegurados de otra parte pudieran acceder a esa especial órbita estatal durante el período de la organización nacional.

\section{Ministro en los Estados Unidos}

La guerra con el Paraguay, "no buscada pero tampoco eludida", durante la presidencia de Mitre fue sumamente impopular, al igual que la alianza con Brasil. La presión reclutadora de hombres para el frente de batalla provocó un movimiento en todo Cuyo, La Rioja y

\footnotetext{
${ }^{35}$ AGN. Fondo J.M. García, Legajo 1134. Carta de Manuel Rafael García a Juan María Gutiérrez, París, julio de 1863.

${ }^{36}$ BCN. Fondo J.M. Gutiérrez. Carta de Manuel Rafael García a Juan María Gutiérrez, Madrid, 7 de enero de 1864.

${ }^{37}$ AGN. Fondo J.M. García, Legajo 1134. Carta de Manuel Alejandro Aguirre a Manuel Rafael García, Buenos Aires, 15 de junio de 1863.
} 
Catamarca que el ejecutivo no pudo controlar y en ese contexto se llevaron adelante las negociaciones para la elección presidencial. ${ }^{38}$

Rufino de Elizalde, percibido como el heredero natural de Mitre, recibió el apoyo del diplomático a su candidatura presidencial esperando que luego del triunfo dividiera en dos las representaciones en Europa, generando una oportunidad de un ascenso:

"Veo por su cartita del último vapor que cuenta Ud. como seguro el triunfo de su candidatura. Reciba desde ahora mis felicitaciones, aunque el estado de los ánimos en nuestro país presagia grandes agitaciones... Antes que llegare Ud. al primer puesto en nuestro país, antes que me sea difícil separar el Presidente del antiguo amigo y compañero quiero que este me diga si algo tengo que esperar en la carrera en que estoy hace cinco años, pues de lo contrario, si el nuevo gobierno no quisiera dividir estas legaciones forzado me será volverme a Buenos Aires a pesar de mis intereses que no van como debieran. Pido este servicio esperando me de un consejo tan franco como mi pregunta ya tengo cuarenta y tantos años y el papel de secretario de Legación ni me sonríe ni me saca de apuros que crecen cada día con mi ya numerosa familia". 39

Sin embargo, el sector nacionalista del partido liberal al cual adscribía Manuel Rafael García fue derrotado por Sarmiento en las elecciones de 1868. De esa forma, su ascenso en la carrera diplomática llegaría de la mano de su antiguo antagonista quien no dejó pasar la oportunidad para incomodarlo: "Mi estimado amigo: le escribo Presidente, saludándolo Ministro Plenipotenciario a los Estados Unidos, según lo deseaba. A muchos no agradaba careciendo Ud. de méritos electorales. Como esta es una deuda que debe pagarse, cuento con que en los Estados Unidos me prestará grandes servicios". ${ }^{40}$ Esa supuesta oposición generada en torno a la designación de García, ¿sugiere el interés que despertaría la vacante entre otros actores? Si el Presidente no destacaba la idoneidad para cumplir las funciones diplomáticas sino la representatividad electoral, ¿qué circunstancias consideraba al distinguirlo? Un factor importante, como se ha visto, más allá de las aptitudes intelectuales y culturales del actor, muchas de las cuales fueron desplegadas como parte de una estrategia de visibilización, se encontraba en el mecanismo de contrapeso del Congreso en la decisión de remover ese tipo de

\footnotetext{
${ }^{38}$ Eduardo Míguez, Historia Económica de la Argentina. De la conquista a la crisis de 1930 (Buenos Aires: Sudamericana, 2008), 70.

39 Repositorio digital Instituto Ravignani, documentos del Dr. Rufino de Elizalde. Carta de Manuel Rafael García a Rufino de Elizalde. Paris, 24 de junio de 1868. Disponible en el Repositorio Digital Institucional de la Universidad de Buenos Aires: $\quad$ http://repositoriouba.sisbi.uba.ar/gsdl/cgibin/library.cgi?a=d\&c=archivos/cartasravi\&cl=CL1\&d=me268000-me268000_pdf >

${ }^{40}$ Cartas Confidenciales de Sarmiento a M.R. García 1866-1872. Carta de Domingo Faustino Sarmiento a Manuel Rafael García, Buenos Aires, 28 de octubre de 1868. (Buenos Aires, Coni Hnos, 1917), 24.
} 
funcionarios. Además el presidente alentaba y admiraba el trabajo literario de Eduarda Mansilla quien acababa de publicar en París su novela Pablo ou la vie dans les pampas.

Con relación al destino asignado, siguiendo a la esposa del diplomático: "la Capital de la Unión, era en ese tiempo considerada por los diplomáticos, una especie de destierro". ${ }^{41}$ Sin embargo, una vez al frente de la legación, desplegó una estrategia diversa a la de su predecesor en ese país. ${ }^{42}$ La posibilidad de comunicarse en inglés y el savoire faire de Eduarda Mansilla, colaboraron para crear un contexto de mayor visibilidad del representante argentino entre los miembros del Cuerpo Diplomático, los funcionarios del gabinete de gobierno, y de cualquier personalidad distinguida en Washington de finales de los años sesenta. Ese posicionamiento, sumado a la iniciativa de la pareja, abrió las puertas de la Legación Argentina para que hicieran su ingreso los exponentes de la política, la diplomacia, y el arte allí presente. Sarmiento, que no imaginó la dimensión que llegarían a adquirir de la mano del interés de la prensa periódica norteamericana por mostrar a sus lectores la educación, el gusto, y las habilidades culturales del matrimonio, tenía a su alcance (por el valor del sueldo asignado en el presupuesto al Enviado) la posibilidad de publicitar la materialización de sus ideales de civilización y progreso y con ello inauguraba su mandato.

La primera recepción fue el 10 de noviembre de 1869: "Madame Garcia, wife of the Argentine Minister gave her first reception last evening which was a very brilliant affair. Gen. Sherman and several members of the foreign legation attended, but unhappily, the gas went out suddenly about 11 o'clock p.m wich prematurely broke up the party". ${ }^{43}$ Luego de ello y sin que volviera interrumpirse el gas, se estableció que los martes serían los días de recibo en la sede diplomática argentina ubicada en I Street. Los periódicos destacaban, asimismo, la excelente calidad de los entretenimientos ofrecidos por los propios anfitriones, entre los que la figura de Madame García realzaba por ejecutar la música y el canto y una de las veladas

\footnotetext{
${ }^{41}$ Mansilla, Recuerdos, 103.

${ }^{42}$ Durante la estadía de Domingo Faustino Sarmiento como titular de la Legación acreditada en los Estados Unidos el actor dividió sus energías procurando en parte la representación cordial del país al mismo tiempo que estudiaba el funcionamiento de algunas de sus instituciones, especialmente las educativas. Las prácticas del Ministro en pos de contrarrestar la atmósfera de opinión sobre la participación de Argentina en la Guerra de la Triple Alianza se vincularon a la publicación de artículos en la prensa periódica. Dan cuenta de ello, el New York Tribune y el Boston Daily Adress. Asimismo fundó en Nueva York una revista de la que circularon tres volúmenes llamado Ambas Américas: revista de Educación, Bibliografía y Agricultura, viendo la luz el primero en el año 1867. Sin embargo, la dificultad para comunicarse en inglés con fluidez y dado que no estableció su residencia en Washington sino en Nueva York, y evitaba asistir a las recepciones, eventos y reuniones del Cuerpo de Diplomáticos, la relación con los actores políticos vinculados al Ejecutivo Nacional o al Congreso fue más bien escasa de acuerdo con los informes enviados al Ministerio de Relaciones Exteriores.

43 The New York Tribune, 17 de noviembre de 1869. [Consultado junio de 2021, disponible en: http://chroniclingamerica.loc.gov/lccn/sn86053571/1869-11-17/ed-1/seq-

2/\#date1=1869\&index=7\&rows=20\&words=Garcia+Madame\&searchType $=$ basic \&sequence $=0 \&$ state $=\&$ date $2=$ $1880 \&$ proxtext $=$ madame+garcia $\& y=7 \& \mathrm{x}=22 \&$ dateFilterType=yearRange $\&$ page $=1$ ]
} 
incluyó mascarada para los niños, de la que participaron los cuatro niños del matrimonio, en el salón del profesor Sheldon en F Street, o las habilidades del mago Herrmann's. ${ }^{44}$

Además de las recepciones, las actividades de la Legación eran múltiples y variadas. Requirió al Ministerio de Relaciones Exteriores la provisión de informes y colecciones de leyes y decretos, fallos de la Corte Suprema, tratados, registro estadístico, memorias ministeriales, la obra de Moussy y la suscripción a los periódicos ingleses Standard de Buenos Aires y Brasil \& RiverPlate Mail de Londres. ${ }^{45}$ Los temas que ocuparon su atención, además de la situación internacional, fueron algunos debates en el Congreso y la opinión pública, entre ellos, uno sobre la aplicación de las doctrinas liberales y proteccionistas en torno de las importaciones, tratando de lograr mejoras para los productos de la Argentina en el mercado norteamericano.

Al mismo tiempo, el gobierno argentino generaba distintos requerimientos que no tendrían un vínculo con la diplomacia stricto sensu, pero que dan cuenta de cómo era percibida esa función en la etapa de la Organización Nacional:

"haga estudios sobre lo que crea útil a nuestro país; mande papeles de gobierno, para el Congreso, los Ministerios, y gaste en ello poquísima plata (...) ¿cuáles son los sellos usados en los Estados Unidos para papel sellado?, ¿cómo se usan? ¿A qué casos y papeles se aplican como contribución - muestras de todos - necesitaría las tarifas de aduana o el sistema adoptado para el avalúo?’. ${ }^{4}$

Los pedidos evidencian el sentido práctico del Presidente, pero también la disparidad de actividades de la legación. Por citar solo algunos ejemplos menos conocidos (ya que el estudio de la educación norteamericana, la selección de maestras y la adquisición de equipamiento para las escuelas excedería ampliamente este trabajo), se alude a los trabajos en torno de la Exposición Nacional Córdoba y la impresión del Código Civil. La primera (inspirada en las realizadas en Londres, París, Viena, Filadelfia y Chicago), demandó contactar con interesados para la construcción del recinto, la convocatoria de inventores, constructores y conseguir que el gobierno norteamericano dispusiera de un buque para el transporte de los artículos. Al sancionarse el Código Civil, Sarmiento, le escribió: "El vapor le entregará a Ud. el Código Civil impreso para que lo haga reimprimir allí. Este es un trabajo de

44 TheEveningStar, 23 de noviembre de 1869. [Consultado junio de 2021, disponible en línea http://chroniclingamerica.loc.gov/lccn/sn83045462/1869-11-23/ed-

$1 /$ seq1/\#date $1=1869 \&$ sort $=$ relevance \& $r o w s=20 \& w o r d s=$ Garcia + Madame \&searchType $=$ basic $\&$ sequence $=0 \& i$ ndex $=14 \&$ state $=\&$ date $2=1880 \&$ proxtext $=$ madame + garcia $\& y=7 \& x=22 \&$ dateFilterType $=$ yearRange \&page $=2$ ].

${ }^{45}$ Archivo del Ministerio de Relaciones Exteriores (AMREE). Correspondencia diplomática de García, Manuel Rafael a Varela, Mariano. Washington, 18 de marzo de 1869. Embajada en Washington Caja ${ }^{\circ} 81$.

${ }^{46}$ Cartas Confidenciales, 24. 
amor que le encomiendo como Ministro y abogado, y como amigo del Doctor Vélez, todo para mayor gloria del autor, del país y del gobierno", ${ }^{47}$ lo cual implicó la búsqueda de presupuestos entre las editoriales que se dedicaban a realizar impresiones en idioma español. De las cinco propuestas, escogió la de Hallet \& Breen de Nueva York que contaba entre sus antecedentes la impresión de otros códigos latinoamericanos y los Trozos selectos de literatura seleccionados por Alfredo Cosson. ${ }^{48}$

Dado que la Legación se integraba con un Secretario y un Oficial, para llevar adelante las diferentes actividades, el diplomático encomendaba, con resultado diverso, tareas a los Cónsules argentinos acreditados en ese país, con quienes mantenía asidua correspondencia: "se ha pedido a todos estos funcionarios dependientes de la Legación una relación de sus trabajos durante el año (...) en cuanto a nuestras relaciones con ellos siendo los agentes naturales de la Legación en las ciudades en que residen, han sido continuamente requeridos para coadyuvar al mejor éxito". 49

De acuerdo con las rendiciones de cuentas del administrador, durante los años 1868 y 1874 no se produjeron enajenaciones de tierra con lo cual, el ascenso en la carrera durante la presidencia de Sarmiento le proporcionó una mayor estabilidad financiera, pese a que el servicio al Estado nunca estuvo asegurado. El propio Presidente Sarmiento le manifestó al Ministro:

"Nada puedo decirle de futuras misiones (...) estando representados aquí todos los países con la misma inutilidad, pero dejando la esperanza de que seamos atendidos cuando algo reclamamos, cosa que no siempre sucede en los países donde tenemos Ministros ojalá puedan conservarse algunas de las actuales embajadas. Hubiera querido nombrarlo miembro de la Corte Suprema aquí, con sueldo vitalicio, poco trabajo, mucho honor y quietud de ánimo, seguro de hacer en ello gran bien al país". 50

La capacidad de gestión demostrada en tan breve período de tiempo, respaldó un nuevo y ambicioso requerimiento.

Por esa comisión, que requería supervisar la construcción de las embarcaciones, se trasladó a Inglaterra y retuvo su puesto de Enviado Extraordinario y Ministro Plenipotenciario cerca del gobierno de los Estados Unidos. La iniciativa de la construcción pretendía recuperar

\footnotetext{
${ }^{47}$ Cartas Confidenciales, 45.

${ }^{48}$ AMREE. Legación Estados Unidos 1869-1870 CAJA AH/0124. Carta de Manuel Rafael García a Nicolás Avellaneda, Washington, 20 de octubre de 1870.

${ }^{49}$ Memoria del Ministro de Estado, 1869, 13.

${ }^{50}$ Cartas Confidenciales, 66-67.
} 
la experiencia norteamericana de la Guerra de Secesión y el ejemplo de los buques del Brasil que habían combatido contra Paraguay. ${ }^{51}$ Con relación a la navegación y la guerra, el pensamiento dominante por entonces se vinculaba a la defensa naval del Río de la Plata y los expertos navales aconsejaban que se adquirieran buques costeros y de río adaptados a los desarrollos torpedo. El Presidente Sarmiento le transmitía sus preocupaciones de esta forma al Enviado:

"Si el Brasil ha ordenado la construcción de dos cañoneras blindadas para bocas de río es claro que seremos encerrados en el nuestro. Las dos que últimamente hemos ordenado para el mar estarían a merced suya o de los acorralados chilenos. Hemos hablado largamente con los Ministros a este respecto y aunque el aumento de gastos puede ser enorme, hemos convenido en autorizar a Ud. para que haga blindadas las dos segundas en las condiciones iguales o superiores a las Brasileras". 52

La comisión culminó en 1876 cuando arribó la última de las unidades, superando ampliamente la iniciativa original en el año 1872, dado que durante el transcurso del tiempo, la experiencia adquirida y el beneficio obtenido del intercambio con la armada inglesa, impulsó al gobierno a contratar la construcción de buques pequeños, maniobrables y con grandes cañones. ${ }^{53} \mathrm{Al}$ mismo tiempo, con el objetivo de formar a los hombres que habrían de utilizar las naves, se creó la Escuela Naval Militar.

Como se ha visto, la supervisión de la adquisición de la escuadra naval no relevó a García totalmente de sus funciones como Enviado Plenipotenciario en Estados Unidos, sin embargo, durante la Presidencia de Avellaneda, ante un ofrecimiento concreto de integrar la Corte suprema, Félix Frías, recibió por respuesta:

"Por el momento, amigo mío yo estoy encargado de la cuestión de límites con el Paraguay y no puedo aceptar, eso creo, una posición por honorable que sea. No hay que pensar en eso por ahora [subrayado en el original] amigo mío. Más tarde ese empleo es el único que me decidiría a aceptar en mi tierra. Cané tiene media razón yo soy incompetente creo para incorporar en la política que él sabe [ilegible] reclamado por la opinión, apoyada por ella (...) En el archivo de R E que vengo señalando desde 1864 pero que está en el pozo de Ayron ¡Ojalá lo

\footnotetext{
${ }^{51}$ Guillermo Oyarzabal, Los marinos de la generación del ochenta. Evolución y consolidación del poder naval en la Argentina (1872-1902) (Buenos Aires: Instituto de publicaciones navales, 2003), 35.

${ }^{52}$ Oyarzabal, Los marinos, 35.

${ }^{53}$ Los buques que conformaron la primera flota naval fueron las cañoneras Paraná y Uruguay (1874), los monitores Los Andes y El Plata (1875) y cuatro bombarderas denominadas Pilcomayo, Bermejo, Constitución y República (1876).
} 
leyeren! Todos los datos que Ud. me pide sobre sobre la tripulación necesaria para nuestros buques fueron redactados a mi pedido por los oficiales de la marina real inglesa y presentados al Ministerio de Marina. No los tengo aquí.". 54

El subrayado "por ahora" exterioriza que es una opción que no descarta y es interesante advertir el tono de la carta que parece denotar decepción en el emisor (porque nadie lee sus informes, porque no se escuchan sus sugerencias). García menciona a Cané, la prensa y las referencias a su ineptitud para convertirse en candidato político, circunstancia que en su oportunidad también le manifestó Sarmiento y que sugieren su autopercepción como funcionario del Estado. Por otra parte, como se ha señalado, su inversión patrimonial fue considerable, y durante el año 1876 principalmente, con lo cual es altamente probable que haya evaluado la posibilidad de retornar al país luego de diez y seis años de ausencia. Así lo pone de manifiesto su administrador:

"mucho me alegra que hayas decidido a esperar a ver más claro. Tu renuncia creo te habría perjudicado. Procuraré hacer lo que me pides sobre títulos de tus propiedades (...) En cuanto a alquileres y sueldos te diré que, los primeros aunque siempre trabajosa y pesada su cobranza se puede decir que va bien sobre todo si se compara con lo que yo tengo ocasión de observar. (...) Los sueldos espero que se seguirán pagando aunque no con la puntualidad que antes... ${ }^{55}$

Al finalizar la adquisición de los buques de guerra, García regresó por unos meses a Buenos Aires tras dieciséis años de ausencia. Durante el gobierno de Avellaneda debió recurrir, más que en otras épocas, a sus propios bienes para mantener su decisión de vivir en el extranjero debido a la crisis política e institucional por la que atravesaba el país; y también debido a la etapa del ciclo familiar que se encontraba atravesando, dado que los dos pequeños niños que acompañaron a sus padres a Norteamérica, comenzada la década en 1860, apenas habían crecido. En Francia, se casaría ese año la primera y única hija mujer con un barón francés que había hecho carrera en el ejército de ese país y Manuel José se había incorporado en la marina de argentina a partir de su egreso de la escuela naval de Brest. En la República Argentina, le informó Aguirre:

"Quisiera poderte decir, como me lo pides, cual es la renta real y efectiva que tú tienes, pero es muy difícil o más bien imposible fijarlo con precisión El Gobierno aún no ha pagado el trimestre que vence en este mes de Setiembre, pero

\footnotetext{
${ }^{54}$ AGN, documento n9602. Carta de Manuel Rafael García a Félix Frías, Washington, 23 de marzo de 1877.

55 AGN. Fondo Los García. Carta de Manuel Alejandro Aguirre Ituarte a Manuel Rafael García, Buenos Aires, 12 de diciembre de 1876.
} 
suponiendo que lo pagará y los siguientes también, lo hará, según entiendo, con un $15 \%$ de rebaja hasta el último de este año y después con un $25 \%$. Con los inquilinos ya no se puede contar como antes: las cobranzas son difíciles y algunas no muy seguras. (...) El cálculo que veo has hecho de arreglarte a solo gastar por todo 7000 francos, me parece bien, bajo la base que tus sueldos se cobren, pero, amigo veo tan malo esto que te aseguro que me cuesta pensar que pueda ser mucho y tengas todavía que reducirte más, si no arreglamos por aquí la situación",56

En 1879, Eduarda Mansilla se reunió con su madre Agustina Rosas en Buenos Aires, ciudad en la que permaneció durante cinco años. Durante ese tiempo el diplomático permaneció en Europa con sus hijos y más allá de las repercusiones familiares de esa separación, la participación de la por entonces consagrada literata en la vida social de Buenos Aires, pero también en su prensa periódica, era alentada por hombres que, al igual que Sarmiento, reconocían su talento cultural.

\section{Consideraciones finales}

La Constitución Nacional puso de manifiesto la preocupación de sus redactores de instituir reglas precisas concernientes al modo de designación de cada órgano del poder federal, las funciones respectivas de cada uno y la manera como se ejercen sus competencias. Sin embargo, al no explicitar cómo se concebía la función administrativa ni la manera en que debía ejercerse, quedó en manos de los presidentes y ministros el diseño institucional de la administración pública. La estructura organizacional del Ministerio de Relaciones Exteriores de la Confederación, que contaba con ocho empleados, subsistió hasta promediar el mandato de Domingo Faustino Sarmiento, cuando se designó un responsable para las tres secciones en que se dividió el órgano: Legaciones y Consulados Argentinos, Autoridades Nacionales, Provinciales, Particulares y Legaciones y Consulados Extranjeros. Fue alcanzado su mayor desarrollo hacia el final de la presidencia de Avellaneda, cuando se incorporaron procedimientos para llevar adelante las tareas. Durante el período de la Organización Nacional, la administración al interior del ministerio acusó los avatares de los cambios políticos renovándose constantemente el personal, con excepción de Pedro Belaustegui y José María Sagasta Isla, quienes enlazaron con su permanencia cada recambio de Ministros. Las

\footnotetext{
${ }^{56}$ AGN. Fondo M.J. García. Carta de Manuel Alejandro Aguirre Ituarte a Manuel Rafael García, 16 de setiembre de 1876 .
} 
legaciones con sede en París y Washington tuvieron una dinámica diferente, donde la continuidad de los diplomáticos se debió en parte al sistema de contrapesos constitucionales que demandaba la aprobación del Congreso para su remoción, evitando que la decisión intempestiva de un presidente lo inclinara a ubicar a sus propios hombres en detrimento de aquellos que teniendo capacidad hubieran sido nombrados en un período anterior. Esa situación se presentó con el triunfo presidencial de Sarmiento frente al sector nacionalista del partido liberal al que adscribía García desde mediados de los años cincuenta.

Las actividades de las legaciones resultaron una pieza clave para la incorporación de muchas de las novedades que se estaban llevando adelante en el exterior, sin embargo, los funcionarios de las legaciones (enviados y secretarios) mantuvieron una actitud frente a su trabajo, un saber hacer, que trascendió a los Presidentes. Dicho de otra forma, las visiones de los Jefes de Estado no influyeron decisivamente en la generación de institucionalidad al interior de las legaciones, con las cuales se habría dado a bien cierto "silencio", al mismo tiempo que se generaban distintos requerimientos que no tendrían un vínculo con la diplomacia stricto sensu, pero que dan cuenta de cómo era percibida esa función en la etapa de la Organización Nacional tales como la organización de la Exposición Universal en Córdoba, la publicación del Código Civil, la adquisición de buques de guerra.

Con respecto a cómo era percibida su tarea, el análisis de los documentos oficiales y la correspondencia privada permiten apreciar la influencia de la personalidad y la experiencia acumulada de cada Enviado en la gestión de su legación. Así, a diferencia de Sarmiento que en Estados Unidos se valió de la prensa para comunicar -una herramienta que conocía y con la que se sentía cómodo a pesar de sus limitaciones con el idioma- y generar un círculo entre educadores, Manuel Rafael García desplegó una estrategia en la que la prensa periódica norteamericana fue sólo una de las herramientas utilizadas en el desempeño del servicio. El conocimiento del idioma y las habilidades adquiridas en las cortes europeas facilitaron su vinculación con las dirigencias políticas residentes en Washington - otro cambio frente a Sarmiento que había vivido en Nueva York-. Su casa se convirtió en un centro de recepciones que concitó la atención de la prensa norteamericana sobre la Legación argentina. Allí se encontraban los miembros del Cuerpo Diplomático de distintos países, junto con los políticos y las autoridades locales, incluido el Presidente Ulisses Grant. La prensa evidencia el papel desempeñado por García y el brillo que daba a los encuentros su esposa, Eduarda Mansilla Madame García como la mencionaba-.

Finalmente, esta investigación pone en evidencia el papel de las personas y sus relaciones a la vez que la generación de institucionalidad en una mutua interacción. 